\title{
La punibilidad del sujeto masculino religioso hoy*
}

\author{
Dalia Carreño Dueñas ${ }^{* *}$ \\ Jorge Martínez Rodríguez ${ }^{* * *}$
}

Recibido: 1 de noviembre de 2015 • Aprobado: 8 de diciembre de 2015

\section{Resumen}

La posmodernidad como la conciencia de los hombres del siglo XXI, trae consigo toda una tendencia secular, que ha generado una fragmentación del sujeto y del discurso que lo gobierna. Así emergen sujetos y discursos por doquier que se auto-legitiman, a través de la exhibición, la intercomunicación y la virtualidad. El sujeto religioso masculino, y su decir se ha debilitado y hoy la penalidad, y su red de sentidos lo configura en peligroso; lo que lo conducen a acrecentar la desesperanza y la no creencia; además de facilitar la fuerza de iconos, sin discurso y sujeto que han tomado su lugar. El orden legal sanciona, crea sujetos infractores para apaciguar los imaginarios colectivos, que alejan del otrora estatus que poseía el hombre consagrado. Queda la alternativa de reconfigurar y recuperar el rol del religioso, como santo en términos del psicoanálisis.

Palabras clave: sujeto, discurso, icono, santo.

* $\quad$ El texto es resultado de la investigación conjunta de los dos autores, desde las líneas y proyectos de investigación que tienen los grupos a los que pertenecen cada uno. DOI: http:// dx.doi.org/10.15332/s2011-9771.2016.0001.02

* Licenciada en Filosofía y Letras, Licenciada en Filosofía y Ciencias Religiosas, Abogada, Especialista en Derecho Penal, Magister en Educación, Doctoranda en Derecho Universidad de Buenos Aires. Docente Universidad Santo Tomás Colombia. Miembro del grupo de Investigación Social y Humanística, clasificado en D. Correo electrónico: daliacarreno@usantotomas.edu.co

*** Doctorando en Educación por la Universidad Santo Tomás, Magister en Teología Moral y Praxis Cristiana, Especialista en Orientación Psicológica, Licenciado en Ciencias Eclesiásticas. Docente de tiempo completo de la Facultad de Teología de la Universidad Santo Tomás y líder del Grupo de Investigación Ethikós clasificado en D por Colciencias. Correo electrónico: jorgemartinez@usantotomas.edu.co 


\title{
The punishability \\ of the religious male subject today
}

\begin{abstract}
Postmodernism as the conscience of the men of the century, brings a whole secular trend, which has led to a fragmentation of the subject and discourse that governs it. So legitimate self-through display, intercom, virtuality and speeches subjects emerge everywhere that. The male religious subject, and say has weakened and today the penalty, and configures network senses dangerous, which leads to increasing despair and disbelief; besides facilitating the strength of icons, without speech and subject they have taken place. The legal order sanctions, creates offenders subject to appease the collective imagination, that keep the status it once had devoted man. The alternative is to reconfigure and restore the role of religious, holy in terms of psychoanalysis.
\end{abstract}

Keywords: Subject, address, icon, saint.

\section{La punissabilité}

\section{du sujet masculin religieux aujourdh'hui}

\section{Résumé}

La postmodernité comme la conscience des hommes du XXI siècle, s'accompagne de toute une tendance séculaire, qui a généré une fragmentation du sujet et du discours qui le gouverne. De cette manière, des sujets et des discours qui s'auto-légitiment émergent de partout a travers l'exhibition, l'intercommunication et la virtualité. Le sujet religieux masculin, et son dire s'est affaibli et aujourd'hui la punibilité, et son réseau de sens le configure de manière dangereuse; ce qui le conduit a accroître le désespoir et la non croyance; en plus de faciliter la force des icônes, sans discours et sujet qui ont pris sa place. L'ordre légal sanctionne, crée des sujets délinquants pour apaiser les imaginaires collectifs, qui éloignent du otrora estatus que possédait l'homme consacré. L'alternative de reconfigurer et récupérer le rôle religieux persiste, comme saint en thermes de psychanalyse.

Mots-clés: Sujet, discours, icône, saint. 


\section{Posmodernidad y sujeto religioso}

La posmodernidad, o lo que bien podría describirse como los tiempos presentes, ha traído consigo una fuerte tendencia secular, o si se prefiere una comprensión no religiosa en términos de reconocimiento fuerte de estructuras tradicionales occidentales como la judeocristiana; no significa que la experiencia espiritual esté ausente, sino que el interés está en otros órdenes, quizá más allá de los sistemas de creencias o unida a la militancia extrema política, y que van delineando la globalización, la virtualidad y el consumo. De esta manera bien se afirma un proceso de radicalización de la secularización de la vida en conjunto ${ }^{1}$, que trae consigo lo propio de las fracturas de los metarrelatos, que funcionaban como pivotes de todas las dimensiones de lo humano. La posmodernidad al fragmentar los discursos, también resquebraja los fundamentos tradicionales del tejido social, lo que pone de presente la urgencia de repensar o actualizar las consideraciones básicas que han de orientar la vida social, desde referentes fuera de los sistema de creencias en donde están presentes categorías asentadas en una moral convencional en versión no dialogante, ni actualizada en las rutas del siglo XXI. El nihilismo y la sospecha han logrado seducir al conjunto social posmoderno, se advierten unos niveles de des-creencia, y de ausencia de apuestas ético-morales en donde valores y principios absolutos, se presentan como deslucidos y sin mayores referentes ${ }^{2}$ que los iconos que los puedan representar en los medios de intercomunicación, y el mundo de las redes. El hombre para afinar su desconfianza se queda solo con el icono, su compromiso se queda con y en él, más allá no genera adhesión; porque el icono esta desvinculado de los referentes fuertes que lo sostienen, así un crucifijo, un hoja de marihuana, un símbolo de las casas de guerra de tronos, un icono de Harry Potter, o del señor de los anillos, un Kaláshnikov tienen el mismo peso y la simpatía moral que evocan, allí en el icono se genera convergencia entre sujeto, discurso, objeto y acción.

1 “El proceso de secularización de la vida social implicó la crisis y caída de la teología y su reemplazo por la filosofía como método de conocimiento, lo que remitía este último a inmanencias y no a trascendencias, a la inteligencias, a la inteligencia y la razón humanas" (Cárcova , 2012, p. 27)

2 “Quién se ha salvado de ese maremoto? Aquí como en otras partes del desierto crece: el saber, el poder, el trabajo, el ejército, la familia, la iglesia, los partidos, etc., ya han dejado globalmente de funcionar como principios absolutos e intangibles y en distintos grados ya nadie cree en ellos, en ellos nadie invierte nada" (Lipovetsky, 2006, p. 35) 
El término sujeto en el contexto posmoderno ha estado inserto para hacer comprensiones en las rupturas de las disciplinas de la filosofía, el derecho y la lingüística ${ }^{3}$, de ahí que en estas epistemologías se tejen los sujetos para poder interpretar su forma de encuentro, autoconocimiento, expresión y acción consigo y con los otros, que para el caso del derecho son definitivas, porque el derecho es práctica social, es con otros, por otros y para otros. El concepto se ha cimentado y transformados en diversas versiones, bien como sujeto gramatical, el equivalente al otro, y el sujeto como singularidad, luego se ha integrado a este último el orden simbólico, el lenguaje, el discurso que lo hace distinto del objeto ${ }^{4}$. Para el orden legal de manera paradójica y más allá de la afirmación de los tiempos globales, el sujeto de derecho, cae como súbdito sujeto al poder del Estado, o si se prefiere sometido, a las rutas multiposibles, pluriversas, exóticas, laicas del hoy, que se configuran en el Otro fuerte que determina, como inconsciente como lugar en el que los infractores son asidos, atrapados y juzgados.

El sujeto religioso termina en este contexto del Otro de su discurso, de descreencia y de fuerza del icono, de objeto o si se prefiere de mercancía, en un lugar en donde están otros, con otros, como otros, lejos de una representación y de un discurso que dice que instaura sentidos y comprensiones de las complejidades de la vida hoy.

La condición del discurso y del sujeto del discurso, entre los que están como otros los religiosos, se encuentran sin prelación, sin categorías, ni jerarquías ${ }^{5}$ lo que hace que estén metacentrados o si se prefiere descentrados, de ahí que surge una pluralidad válida y legitima de sujetos y discursos, con voces, fuerzas y lugares en los cuales los ubican los medios y las intercomunicaciones. La pluralidad de sujetos, discursos y objetos, más allá de la hegemonía de los otrora sujetos y discursos religiosos, posibilitan una amplia gama de opciones de espiritualidad o

3 "Está más asociada con los discursos filosófico, jurídico y lingüístico" (Evans, 1997, p. 184).

4 “En 1945 Lacan distingue tres tipos de sujetos el puro sujeto gramatical.Segundo, está el sujeto reciproco anónimo y que se reconoce como equivalente a otro. Tercero el sujeto en su singularidad el sujeto es parte del orden simbólico".

5 “Nuestra sociedad no conoce prelación, codificaciones definitivas, centro, sólo estimulaciones y opciones equivalentes en cadena. De ello proviene la indiferencia posmoderna, indiferencia por exceso, no por defecto, por hipersolicitación, no por privatización" (Lipovetsky, 2006, p. 39). 
de formas de asegurar respuestas a las decepciones ${ }^{6}$, encrucijadas y a los retos que plantean el mercado, el consumo y las tecnologías; la espiritualidad cae en la multiplicidad de los objetos que se ofrecen a todos, como iconos puros exhibidos, concentrados, mutantes en la interconexión y en la intercomunicación. Se asumen, por lo tanto, sujetos y discursos con pasotismo, porque están afectados a la manera de objetos de consumo, que proliferan y que son reemplazados una vez se agotan, o aparece un nuevo modelo o una serie. Es posible que el desencanto posmoderno por los sujetos y discursos tradicionales, causen la falta de sorpresa, de escándalo, de sentido, porque persiste la sensación de que todo está minado por lo cotidiano en que han caído los referentes de la vida social. El sujeto religioso y su discurso está en el contexto de indiferencia ${ }^{7}$, apatía y decepción porque representan lo estable, lo permanente, quizá lo reservado y oculto; a lo cual el hombre posmoderno no se sujeta, no se adhiere porque la movilidad, la mutación es permanente y para que un sujeto o un discurso permanezca, tenga cierta recordación, genere opinión tiene que ser plástico, alucinante, sobreexpuesto... mientras es reemplazado por otro, por su carácter provisional.

\section{El sujeto, el discurso, el objeto religioso como icono}

La hipersecularización ubica otras preocupaciones, consolida no ya líderes o caudillos, crea héroes, antihéroes, a quien seguir, figuras icónicas paradójicas ${ }^{8}$ porque se presentan en los límites claro-oscuros de la razón práctica, pero que despiertan clubes de seguidores, fans, followers y que bien pueden ser actores, personas del común, personajes de tiras cómicas, o versiones pop o cool de las religiones, todos

6 "Para combatir la decepción, las sociedades tradicionales tenían el consuelo religioso; las sociedades hipermodernas utilizan de cortafuegos la incitación incesante a consumir, a gozar, a cambiar" (Lipovetsky, 2008, p. 23).

7 "El hombre indiferente no se aferra a nada, no tiene certezas absolutas, nada le sorprende, y sus opiniones son susceptibles de modificaciones rápidas: para alcanzar un grado tal de socialización, los burócratas del saber y del poder tienen que desplegar tesoros de imaginación y toneladas de informaciones" (Lipovetsky, 2008, p. 44).

8 Como el caso paradigmático del personaje de Jack Bauer de la serie 24 horas, en donde este agente, parece justificar acciones como la tortura, el homicidio, en aras de bienes mayores como la seguridad del Estado amenazado por el terrorismo. Otro personaje bizarro, Rick Grimes de la serie The Walking Dead, se erige como icono posmoderno, quien en condiciones extremas de supervivencia, agota los diques morales de la dignidad, la libertad en un Estado ausente, y en instituciones arruinadas. Sin desconocer la fuerza de héroes entre cantantes y actores como Justin Bieber, Angelina Jolie y demás, según los niveles de aparición y venta de sus productos. 
circulando en las redes. La manera como estos sujetos icónicos emerge y se posesionan en el rol de cohesión o adhesión colectiva, es a través de la desformalización, como quiera que no representan instituciones ni expresiones de tradiciones, historia o religión, que han ingresado a las listas de la desconfianza y el desencanto. Esta desformalización del sujeto y del discurso que lo gobierna abate limites, y por ello permea los intereses, las sensibilidades, la apuesta moral, ética y política de todo fan.

Sujetos y discursos mediáticos, como celebridades junto a sus fans ${ }^{9}$, logran minar la confianza en los nombrados sujetos y discursos que orientaban y se entronizaban como sujeto-discurso de autoridad, como el Estado, los jueces, los políticos, los padres, educadores, religiosos entre otros, no hay sujeto-discurso el cual resista la criba del consumo, la exhibición, la provisionalidad, y menos aún la inversión en seudoobjetos. Se advierte un punto de no retorno, de la preponderancia del objeto y su conquista de discurso ${ }^{10}$, como relativo al mercado y a la incertidumbre, que incide en el inicio del olvido del sujeto y del discurso, como objeto de análisis y centro de las fuerzas de la vida en común.

Los roles de los sujetos y discursos posmodernos en tanto celebridades, se instituyen a manera de objetos, lo que implica que estos estén inscritos y representen las demandas, circulación y posición del derroche, que converge en su icono. El fuerte del seudo-objeto, es que logra sujetar a otros, más allá del contenido de su propia representación, de ahí que se configuran en sujetos de reproche o reconocimiento, según la labilidad de su presencia o ausencia. Y de manera paradójica la fragilidad del seudo-objeto es la transitoriedad que lo preside y le obliga a un performance constante, para sostener el mercado de su propia imagen, los sujetos y el discurso posmoderno para estar presente, exhibido, actual ha de estar a la vanguardia, innovando, mutando para asegurar su valía. Frente a los sujetos y discursos en tanto objetos, los religiosos en el siglo XXI, antes denominados;

9 "El Superyo se presenta actualmente bajo la forma de imperativos de celebridad, de éxito que, de no realizarse desencadenan una crítica implacable contra el Yo (...) América se ha convertido en una nación de <<fans $\gg$ Así como la proliferación de los consejeros médicopsicológicos destruye la confianza de los padres en su capacidad educativa y aumenta su ansiedad, asimismo las imágenes de felicidad asociadas a las de celebridad engendran dudas y angustias" (Lipovetsky , La era del vacío , 2006, pág. 73).

10 “Un punto de no-retorno en el que no sólo toda posición del sujeto analítico está afectada de relatividad y de incertidumbre, sino que la supremacía está completamente invertida: el objeto analizado triunfa hoy en todas partes, a partir de su posición de objeto, del sujeto del análisis. Se le escapa por todas partes, le remite a su posición inencontrable de sujeto" (Baudrillard, 2000, p. 83). 
sujetos y discursos encargados de la salvaguarda de la moral, la ética y la espiritualidad privada y pública, están por antonomasia hoy día en otra dimensión, en rutas y coordenadas obsoletas en donde no hay representación, y difícilmente sostienen un nicho simbólico propio, su icono perdió vigencia, expiró para el hombre posmoderno, su performance no se mantiene ni logra innovación, su discurso no dice, su exhibición y sobreexposición no preside las tecnologías, así, que se configura en un sujeto que no sujeta por la cada vez mayor ausencia de fans, seguidores o followers. Por la publicidad, y sobre-exposición de las acciones reprochables de algunos de ellos, el imaginario social sobre el sujeto consagrado y sagrado, en tanto seudo-objeto también, se ha tornado en sujeto peligroso objeto de toda censura y castigo ejemplar, porque ha defraudado las expectativas sociales de lo sagrado, el honor, la dignidad, el respeto depositadas en él. De manera paradójica quien era sujeto, en tanto modelo de vida moral y ética a seguir, hoy se ha convertido en sujeto modelo a castigar a condenar por lo reprensible de sus acciones. Hoy se erigen, religiosos, sacerdotes, religiosas, comunidades, e institución como tales en objetos de castigo, generadores de desconfianza, sometidos al escarnio público, que permiten las intercomunicaciones, los medios tecnológicos cada día más accesibles, amigables y parte de la vida diaria de todos los hombres posmodernos, virtuales.

La caída del sujeto religioso como garante de unidad y valores fundantes, ha proporcionado recursos, elementos e insumos al consumo, la globalización y la virtualidad para construir, crear o customizar nuevos sujetos de respuesta, convocatoria y adherencia social; sin que sean estables, firmes o siquiera con un mínimo de referencia en la vida cotidiana, basta con que tengan seguidores. El derrumbe del sujeto religioso, y por lo tanto del discurso que lo sostenía y lo mantenía en lo oculto, en el misterio en lo sacro de su representación y de su persona misma, hoy esta des-oculto, esta des-velado y de manera radical está expuesto, exhibido, presente, on line; así ante este desocultamiento solo queda la transparencia ${ }^{11}$, la cotidianidad, de ahí las dificultades para poder decir algo nuevo o novedoso decir, o instaurar un discurso para la espiritualidad posmoderna, no de manera necesaria mayor de edad. Esta quiebra del sujeto religioso encuentra eco,

11 "Si esta definición de la contemporaneidad, que comporta sin duda un reajuste radical de la misma noción de historia, no se quiere llevar hasta sus consecuencias extremas y vertiginosas, se podrá reconocer, no obstante, lo razonable de otro aspecto ligado a esta hipótesis, esto es: que a la luz de este enfoque los ideales sociales de la modernidad se muestran unitariamente descriptibles como guiados por la utopía de la absoluta autotransparencia" (Vattimo, 1998, p. 96). 
lugar en la mutación posmoderna en donde los sujetos una vez adquieren, por la provisionalidad y la exhibición, el carácter de objeto, de intercambiabilidad, y por lo tanto ya no puede como sujeto-objeto decir, crear nada, no queda alteridad ${ }^{12}$ fuerte, inclusión, reconocimiento a la diferencia que salvaguardar, ni categorías de encuentro que sostener. La alteridad está invertida y paradójica, porque se acrecienta a manera de nuevas premuras sociales, el reconocimiento entre iguales, pero en versiones asimétricas, diferentes, distintas, se marca la urgencia de pertenecer a algo, como expresión de mixofobia ${ }^{13}$ en pequeño, en limitado, a manera de islas, unidos por iconos, seudo-objetos banales que se dan en los grupos, en tribus, seguidores, fans, amigos pero como iconos, sin mayores esfuerzos por el diálogo, los afectos, el conocer y aceptar al otro. Una alteridad paradójica, sin más, sin esfuerzo y a la medida de las necesidades de lo novedoso, del consumo, de lo que une sin compromisos ${ }^{14}$ por el conocer al Otro, es quizá un apego en superficie; pero al que es posible dar la vida, a manera de fanatismo o devoción hoy por hoy la camiseta del equipo, la bandera del grupo, el kalashnikov, entre otros. En este escenario de la retirada o reactualización de la alteridad que resulta compleja y problemática y quizá liquida, el sujeto religioso y el discurso que le pertenece tiene espacio limitado, cercenado, por demás anómalo o extraño, porque su vocación es inclusiva, universal, de prójimos, mientras que la alteridad posmoderna es de fans, seguidores, de identidad construida por la celebridad del grupo, para el grupo.

12 "Eso es exactamente lo que ha desaparecido, la buena y tradicional alteridad de la relación, la buena y tradicional inversión del sujeto en el contrato y el intercambio racional, espacio a un tiempo de la rentabilidad y de la esperanza. Todo eso deja lugar a un estado de excepción, a una especulación insensata, que tiene tanto de duelo como de provocación. La toma de rehén es una especulación de ese tipo: efímera, insensata, instantánea. No tiene, por tanto, esencia política, se inscribe de entrada como nostalgia de un trato fantástico, nostalgia de un intercambio imposible, denuncia de la imposibilidad de ese intercambio" (Baudrillard, 2000, p. 50).

13 "La mixofobia se manifiesta en el impulso a buscar islas de similitud e igualdad en medio del mar de la diversidad y la diferencia. [...] Los orígenes de la mixofobia son banales, se encuentran sin necesidad, son fáciles de comprender aunque no tanto de perdonar" (Bauman, 2010, p. 124).

14 "La tendencia a buscar una <<comunidad de semejantes $>>$ es una señal de retirada de la alteridad exterior y también de la renuncia a comprometerse con la interacción interior, vital aunque turbulenta, estimulante pero molesta. El atractivo de una <<comunidad de semejantes $>>$ es el de una póliza de seguros contra los múltiples peligros que comporta la vida cotidiana en un mundo multilingüe" (Bauman, 2010, p. 125). 
Por demás, el lugar preponderante y privilegiado, en donde se construye esta alteridad en versión light, o suave, está en las redes, en los bits y a un clic de interacción, el vínculo se genera a través de las intercomunicaciones, de lenguajes y símbolos emergentes, con una representación en sentido débil, porque no pretende universales. Esta construcción de hiperalteridad plástica reconstruye los vacíos, las debilidades y las expectativas no cumplidas de los metarrelatos hegemónicos ya superados, que representan entre otros los sujetos religiosos, porque aparecen como extraños, ajenos e incomprensibles ${ }^{15}$. Como signo que marca las tendencias posmodernas, la alteridad a la medida como paradójica, crea las condiciones óptimas para que no sean posibles la comprensión por el otro, en tanto igual pero diferente, ni tampoco para poder tener simpatía o empatía moral, con el otro, el otro en tanto ajeno, extraño, des-centrado, no prójimo, lo que facilita que los sujetos sean opacados, diluidos en las complejas formas de existir y de encuentro en el universo de la virtualidad. La religión, o quizá el fenómeno religioso y el sujeto religioso, se encuentran diluidos o quizá sustituidos y desplazados, por la manifestación de la alteridad como virtualidad, que posibilita otras formas de encuentro, adhesión y compromiso, que se anidan en disposiciones, arquitecturas ideológicas, profanas, políticas, o de violencias ${ }^{16}$, de mayor sentido, entidad, y apasionamiento, que el sujeto religioso, diluido, en abandono no logra hiper-alteridad, ni vinculatoriedad de la misma forma.

De manera paradójica la alteridad que era afirmada como acercamiento, privilegio del cara a cara, encuentro, interioridad, desvelamiento del rostro, intersubjetividad que posibilitaba la construcción del mundo social ${ }^{17}$, en donde el otrora sujeto religioso tenía un discurso que le legitima un decir, y en el que podía señalar horizontes de encuentro. En versión posmoderna esta se circunscribe a los

15 “Los extraños tienden a parecer más aterradores cuando más ajenos, desconocidos e incomprensibles llegan a ser, y a medida que van desapareciendo, o dejan de arrancar, el dialogo y la interacción mutuos, que podrían terminar asimilando su $<<$ alteridad $>>$ al mundo propio" (Bauman, 2010, p. 126).

16 "De la misma manera que la religión se ha realizado definitivamente en otras formas, irreligiosas, profanas, políticas, culturales en la que es ilocalizable como tal (incluyendo el revival actual, en el que toma la máscara de la religión), también la crítica de las técnicas virtuales enmascara el hecho de que su concepto está destilado por doquier en la vida real en dosis homeopáticas" (Baudrillard,2009, pág. 44).

17 “La valoración de sí mismo posibilita la valoración de las relaciones interpersonales en función de sí y en función del otro; la dimensión interpersonal profunda afianza la interioridad, la enriquece y la proyecta hacia mundos complejos de interrelación. La génesis personal remite a la alteridad y el cultivo de está, genera las aptitudes y habilidades sociales" (Yañez, 2003, p. 249). 
escenarios de las tecnologías, las intercomunicaciones, los bits y todo y todos vinculados a un clic de distancia. La alteridad posmoderna está en los hipermundos que crean las posibilidades del me gusta como expresión de intersubjetividad entre sujetos-objetos, sujetos-programas, amigos, afectos, y amores en la red, pero etiquetados como amigos, followers, fans que despiertan, más allá de lo simbólico o el sentido propio que le pertenezca; afectación de la subjetividad. La intersubjetividad en las intercomunicaciones, se construye desde lo teratológico, lo sublime, lo decoroso, lo púdico, obsceno, incluido lo elemental, lo banal y lo intrépido de las acciones, allí en todo este multiverso está la alteridad, más allá de la corporalidad, del rostro. En la virtualidad todo está incorporado sin más, como lo está la alteridad en la liviandad, en lo light de los individuos, las instituciones, las normas, los compromisos, las jerarquías y las censuras las introducen los seguidores, los grupos, los amigos. El sujeto religioso está fuera, es pesado porque es un rostro que es pura significación ${ }^{18}$, rostro y discurso en unidad ${ }^{19}$ como sentido fuerte, pero que de manera contradictoria aparece vetusto en categorías que no despiertan alteridad en versión suave, provisional, hiper, virtual no hay forma de que genere empatía ni simpatía moral. Está en la mira de la sospecha porque representa unidad, autoconciencia, no fisuras, universalidad, como sujeto que representó la modernidad ${ }^{20}$, y que hoy se entroniza como un sujeto en huida de la singularidad para afincarse de manera fuerte como plural, fractal, multiforme, multiposible, diverso, descentrado, global, en movimiento ${ }^{21}$, creado por otros, como otros. Un sujeto único no es dialogante, cercano, abierto, un sujeto como

18 "El rostro es significación, y significación sin contexto. Quiero decir que el otro, es la rectitud de su rostro, no es un personaje en un contexto. [...] Y toda significación, en el sentido habitual del término, es relativa a un contexto tal: el sentido de algo depende, en su relación, de otra cosa. Aquí, por el contrario, el rostro es, en él sólo, sentido" (Lévinas , 2008, p. 72).

19 "Rostro y discurso están ligados. El rostro habla. Habla en la medida en que es él el que hace posible y comienza todo discurso" (Lévinas , 2008, p. 73).

20 "Pues no hay duda de que la modernidad estuvo, como proyecto dominado por una filosofía de la subjetividad, compacta, autoconsciente, sin fisuras, que se creyó capaz, en su uso de una razón universal, de liderar un proceso encadenado y ordenado de acontecimientos dirigidos a la emancipación humana" (Ruiz de Samaniego, 2004, pág. 40).

21 “El sujeto deja, pues, de ser algo estable en la certeza de sí mismo para difractarse en una multiplicidad de personas (máscaras) que lo habita por dentro en este sentido, la crisis nietzscheana de la subjetividad no debe entenderse tanto como una extinción del yo cuanto como una pluralización y deriva, muy cerca a las tesis defendidas por el posestructuralismo deleuziano, por ejemplo [...]" (Ruiz de Samaniego, 2004, p. 40). 
Otros y en otros, será para el mundo posmoderno bimilenario un sujeto metacentrado, comprensivo, con un multidiscurso de multidecires, de rostros.

El sujeto religioso como singular, moderno, lineal no genera mayor simpatía moral, que la que generan los iconos fuertes del consumo, bien por la representación o lo simbólico de su imagen en las rutas del mercadeo, del consumo de las tecnologías. Esta tendencia laica, desacralizada como expresión del siglo XXI dispersa las bases estables del pensar, afinca la diversidad, los discursos divergentes, y consolida el discurso anormal. También resquebraja la idea de unidad o de convergencia de una única versión de la historia ${ }^{22}$ alrededor de un sistema de creencias, lo que abre espacios a otras formas, otros discursos para cohesionar otros sujetos. De manera difícil se sostiene un sujeto, o sujetos a los cuales poder adherirse o sin desconfianza asumir el discurso, que lo gobierna. Si los discursos están deslegitimados los sujetos del discurso también entran en la crisis del mismo; entonces discurso y sujeto de discurso están insertos en la fragmentación, en la deslegitimación, en la desregulación, en una extendida y desplegada sospecha $y$ desencanto como marca epocal. Lo que incide en la creación de nuevos sujetos, que se construyen por el discurso jurídico para su reconocimiento, su garantía, el reclamo de un lugar en lo social, y también como sujeto de punibilidad, como consecuencia lógica.

Ante la crisis de los discursos y los sujetos de estos, que como emergentes, ocupan los lugares en donde sucede o se suceden la integración de aspectos o elementos de lo social, dada la desintegración que define al hombre, al derecho y a todos los fenómenos culturales como propios de la posmodernidad. Así lo paradójico se apodera y se extiende en la posmodernidad, porque al no imperar un sujeto, ni un discurso que concite, entonces cualquiera incluso un objeto de consumo lo hace ${ }^{23}$, o bien un evento, en tanto icono, o figura con seguidores. La adherencia, como sentido de lo social está descentrada, y mutada, es un metacentro, al

22 “(Según una vía iniciada, antes que por Benjamin, ya por Marx y Nietzsche) se desemboca en la disolución de la idea de historia como curso unitario; no hay una historia única, hay imágenes del pasado propuestas desde diversos puntos de vista, y es ilusorio pensar que haya un punto de vista supremo, comprensivo, capaz de unificar todos los restantes ( tal sería el de $<<$ la historia $>>$ que englobaría a la historia del arte, de la literatura, de las guerras, de la sexualidad, etc.)." (Vattimo, 1998, p. 76).

23 "Nuestra situación paradójica es la siguiente: como nada tiene ya sentido, todo debería funcionar a la perfección. Como ya no existe un sujeto responsable, cualquier evento, incluso mínimo, debe desesperadamente ser imputado a alguien o a algo: todo el mundo es responsable, una máxima responsabilidad flotante está ahí, dispuesta a apoderarse de cualquier incidente" (Baudrillard, 2000, p. 36). 
que se puede estar unido por sentimientos, banderas, símbolos, acontecimientos, clics, colores, causas fútiles, todos aspectos como fuerte tendencia, aunque con fecha de expiración, una vez agotado el discurso, que termina como provisional. Ante esta tendencia posmoderna sigue vigente la pregunta en clave del siglo XXI ¿qué mantiene unida a la sociedad ${ }^{24}$, porque el sujeto y discurso religioso está en decadencia y no es quien la une.

\section{La construcción del sujeto religioso como ofensor emergente}

La sociedad a lo largo de su historia ha construido sujetos ofensores, que terminan siendo recogidos para su criminalización por el orden jurídico, que es una más de las expresiones de la cultura, de lo que van delineándose en la vida en común. Es la sensibilidad social la que considera quien, o qué acciones de los hombres es objeto de sanción, señala qué debe seleccionarse como tal para que sea castigado, esta discriminación obedece a la red simbólica que integra la política, la economía, la religión, la moral entre otras, que configuran la institución social de la punibilidad. El objeto o los objetos de sanción, se configuran a través de las acciones reprochables se van escogiendo, se van discerniendo según los juegos del discurso y las estrategias de intersubjetividad. El juego del lenguaje ${ }^{25}$ de la punibilidad consiste en que el sujeto es marcado por el discurso, que se le recrimina, por la palabra que le instaura sentido, así pasa de ser individuo ofensor a mero criminal, ofensor en sí mismo. Al endilgar al sujeto, se instaura el discurso-sujeto como uno solo, como un individuo. En el caso del sujeto religioso actual en decadencia o puesto en cuestión, queda signado por la palabra ${ }^{26}$ que encierra el juicio de la punibilidad posmoderna que lo precisa en categorías de ser parte, cómplice,

24 “La pregunta <<qué mantiene unida a la sociedad?>> se plantea de nuevo, una y otra vez, en cada época y también en cada ámbito cultural. Para las democracias modernas, fundadas sobre la igualdad y la libertad de sus ciudadanos, debemos la más escrupulosa investigación sobre el tema a Alexis de Tocqueville" (Grimm, 2007, p. 29).

25 "La pregunta <<qué mantiene unida a la sociedad? > se plantea de nuevo, una y otra vez, en cada época y también en cada ámbito cultural. Para las democracias modernas, fundadas sobre la igualdad y la libertad de sus ciudadanos, debemos la más escrupulosa investigación sobre el tema a Alexis de Tocqueville" (Grimm, 2007, p. 29).

26 ¿Qué designan, pues, las palabras de este lenguaje? - ¿Cómo debe mostrarse lo que designan si no es en su modo de uso? Y ya lo hemos descrito. La expresión «esta palabra designa esto» tiene que convertirse también en una parte de esta descripción. O: la descripción debe hacerse en la forma «La palabra... designa...». (Wittgeintein , 1999, p. 7). 
actor de delitos contra menores, y como sujeto opaco y paradójico queda atrapado en el discurso de la sanción penal, y de los reproches sociales.

El sujeto religioso como infractor per se, como resultado de la construcción social del discurso punitivo, atravesado por todos los órdenes sociales está enclaustrado dentro de este discurso, del que es complejo sustraerse, más allá de si sus acciones están o no dentro de estos escenarios de reproche. Queda sujetado el sujeto religioso, al orden jurídico, de manera fuerte, porque se ha identificado como infractor, como delincuente, de manera preponderante de un sujeto de vivísima sensibilidad y de prevalencia fuerte de derechos, amparos y garantías: los menores de edad, los niños. Cuya protección especialísima y condición lo ubican en un lugar de privilegio, y de halo de blindaje y de intocabilidad, que recrudece y magnifica cualquier forma de transgresión, por mínima que esta sea, y si esta la produce un sujeto y un discurso en crisis, con mayor severidad será juzgado. La sociedad posmoderna y su punibilidad ha logrado el consenso de proteger y dedicar los esfuerzos para salvaguardad al menor. Así el sujeto religioso y su discurso peligroso es ideológico ${ }^{27}$, como resultado del nicho ideológico, que se configura por la red de sentidos que los hombres, en tanto individuos y colectivos, lo han instaurado, por los mundos de los cuales se ha nutrido y tejido como tal, de ahí que bien se podría afirmar: no dejen que se acerquen los niños a ellos. La dimensión ideológica del derecho se concreta cuando selecciona y recluta ${ }^{28}$ individuos que se transforman en sujetos punibles, como el sujeto religioso peligroso, de estos tiempos, para que sean el blanco de la pena, para que se cumplan los fines de la misma, entre los que está el hecho de que el Otro, (como imaginario o concepto del religioso) y los otros religiosos sean afectados con estos castigos para prevenir que repitan estos actos ilícitos, reprensibles en contra de un sujeto con prerrogativas amplias.

Los movimientos sociales de manera ideológica coadyuvan en la construcción y determinación, del nicho simbólico que conforma la penalidad ${ }^{29}$, el castigo,

27 “La ideología es, por lo tanto, la expresión de la relación de los hombres con su "mundo" es decir la unidad (sobredeterminada) de su relación real y de su relación imaginaria con sus condiciones de existencia reales. En la ideología, la relación real está necesariamente investida en la relación imaginaria" (Ruiz, 2006, p. 100).

28 "La ideología actúa y funciona de manera tal que "recluta" sujetos entre los individuos (los recluta a todos) "trasforma" a los individuos en sujetos (los transforma a todos) por medio de esta operación muy precisa que llamamos la "interpelación", la cual puede ser representada según el tipo mismo de la interpelación policial más banal de todos los días: "eh, usted allí" (Ruiz, 2006, p. 100).

29 "Se considera el castigo como el procedimiento legal que sanciona y condena a los trasgresores del derecho penal, de acuerdo con categorías y procedimientos legales específicos. 
la pena aplicable que merece el infractor desacralizado, secularizado, y en decadencia junto a su discurso, como el que se ha instituido con el sujeto religioso peligroso. Los rituales del castigo tienen el propósito de afectar a esta misma sociedad, que a manera de círculo entre deseo de castigo y satisfacción del mismo, se cierra cuando el sujeto es penado, sometido y ha recibido la venganza por la ofensa; desagravio que conlleva para este sujeto religioso, una sobre-exposición, extra-repudio y una magnificencia de las acciones ofensivas, por el agravio al sujeto salvaguardado, protegido: el menor. De ahí que una vez asido al orden legal punitivo, a la potentia punible del Estado, a la violencia instituida e institucionalizada, explicita manifiesta que como amenaza ${ }^{30}$ se conforma en legitima, permitida y justa, y que implica que el sujeto atrapado, de manera difícil pueda zafarse del poder y de la fuerza desplegada por este, fuerza que es traducida también en un discurso y en unas representaciones ${ }^{31}$ de persecución, de juzgamiento, de proceso y de limitación de derechos, como propias del andamiaje del orden legal.

El escenario jurídico per se es violencia por el poder otorgado como ejercicio del ius puniendi del Estado, violencia que conlleva incluso una arquitectura simbólica de constreñimiento, de segregación, en la cual ocupa un lugar de dominación para someter al ofensor, en este caso el sujeto religioso masculino de manera especial, frente al cual los valores cristianos de la caridad, el perdón, el amor no tienen cabida. Y quizá esté manifiesta una penalidad fuerte, cargada de sentido, de rechazo al sujeto religioso ofensor por la decepción de la confianza depositada y la ruptura de su compromiso de cuidado de las almas.

Ahora el sujeto religioso instaurado, marcado y además ya reclutado en este albor del siglo XXI, como ofensivo, peligroso, se ha configurado en sujeto de imputación, juicio y de sentencia, sin las prerrogativas o consideraciones que otrora

Este proceso, complejo y diferenciado, se conforma de procesos interrelacionados: legislación, condena y sentencia, así como administración de las sanciones. Involucra marcos discursivos de autoridad y condena, procesos rituales de imposición del castigo, un repertorio de sanciones penales, instituciones y organismos para el cumplimiento de las sanciones y una retórica de símbolos, figuras e imágenes por medio de las cuales el proceso penal se representa ante los diversos estratos de la sociedad" (Garland, 2010, p. 33).

30 “[...]Esta concepción del derecho está compuesta por retórica, burocracia y violencia la violencia es una forma de comunicación y una estrategia de toma de decisiones basada en la amenaza de la violencia física" (Santos , 1998, p. 20).

31 "La ideología es mostrada como una práctica social. Esa práctica social puede ser entendida como un sistema de discursos que se caracteriza por un peculiar mecanismo (reconocimiento-desconocimiento), que produce un efecto pertinente: representaciones" (Ruiz, 2006, p. 101). 
poseía, y que estaban justificadas por los respetos, las distancias, los imaginarios y las prácticas de la vida religiosa y espiritual en común, y que lo sustraían de la justicia de los hombres, y lo ubicaban en la condición de sujeto consagrado por fuera de la imposición de castigos por parte del Estado. Porque no era posible para el colectivo, que mutara en transgresor, y menos que lo hiciera en contra de un sujeto de protección especialísima. De esta manera no puede sustraerse la dimensión moral ${ }^{32}$ que lleva ínsita, toda la penalidad que recae sobre el religioso delincuente, porque ha defraudado la moral, el orden social establecido, que implica que dentro de la vida en conjunto se designen individuos con tareas particulares, con una alta confianza para este encargo. Esta carga moral explica la intensidad, la hiper-exposición, el escarnio y el furor por el agravio, quizá podría entenderse como la decepción moral, la desilusión en la esperanza del porvenir, el desencanto por lo sólido, la estructura, lo fuerte, lo permanente.

\section{De la historia de otros sujetos de la punibilidad}

Los sujetos de castigo, y el castigo mismo se han ido modulando de manera histórica, de tal suerte que los sujetos a quienes se les ha de castigar, se van creando y se van haciendo también con todos los dispositivos de las formas de castigo, el castigo público, y los lugares de castigo. Además del arraigo y la aspiración colectiva de que se haga justicia, y que el desequilibrio que ocasionan las ofensas, vuelva a retornar en armonía y apuestas de vida común. De igual manera el castigo, las penas, y la intensidad de estos han mutado desde la crueldad sobre el cuerpo, como la tortura, los trabajos forzados, las multas y la prisión entre otros; todas penas que al día de hoy han fracasado ${ }^{33}$ porque no resocializan, ni reconcilian al ofensor con las víctimas y el colectivo ofendido, pero que se mantienen, como expresión de la pasión por la sanción y la venganza trasladada a Estado.

32 "Las interrogantes de Durkheim sobre la base moral del derecho penal, el involucramiento de los espectadores en el proceso penal, los significados simbólicos de los rituales penales y la relación de las instituciones penales con el sentimiento público, son dignas de la mayor atención" (Garland , 2010, p. 43).

33 “[...] La prisión siempre ha sido un fracaso, si bien ha tenido importantes efectos políticos en un nivel social más amplio; por ello nunca se le ha abandonado los defectos de la prisión-su ineficacia para reducir el crimen, la tendencia de producir reincidentes, a organizar el medio criminal, a dejar en el desamparo a la familia del delincuente etc.- se reconocen desde el decenio de 1820" (Garland , 2010, p. 180). 
Verbigracia lo que sucede con la prisión, por los beneficios prestados a la punibilidad posmoderna, ideológica, capitalista, excluyente.

Otros sujetos peligrosos han emergido y han dejado su huella como seres malignos, estos han evolucionado hasta dejar de ser sujetos atrapados por la penalidad de su tiempo, y ser incorporados a los imaginarios sociales de personas aceptadas, incluidas y con roles protagónicos. De esta forma el sujeto peligroso puede cambiar, una vez ha sido sujetado por el derecho. Uno de los aspectos paradigmáticos de estos sujetos creados y mutados, es la pregunta fundamental por el ¿quién eres $?^{34}$, porque si bien parece un individuo, en realidad congrega la red de sentidos, intereses, poder, ideología que lo instauran. De ahí que no sólo se requiere que sea el sujeto que cometió el delito, quien sea objeto de indagación, de juicio, sino que lleva a que éste explique, la razón de sus acciones, como quiera que está sobreexpuesto, y ante la mirada y voz de todos, gracias a las interconexiones, y a la inmediatez de la información, se requiere que de una vez aclare, lo que es él. Como aparece en tanto figura mediática, es urgente que se explique, porque ahora pertenece a todos, a la comunidad global, y ante estos sujetos peligrosos la explicación de la locura no es suficiente, porque aparecen como buenas personas, en algunos casos ciudadanos ejemplares y comunes. Estos sujetos peligrosos son cercanos, cotidianos, son padres, madres, hijos, vecinos, no están en un lugar extraordinario, están dentro de la esfera doméstica ${ }^{35}$. Quizá un sujeto por antonomasia que mejor permite la explicación de la institución social que representa la punibilidad y su práctica, creado para ser castigado y escarmentado, fue la mujer, quien en la edad media termina siendo construida como sujeto maligno, -culpable- en ultimas bruja, a quiene era necesario juzgar por el delito de brujería y por los actos en contra de los varones, víctimas de su maldad. Las mujeres eran maleficiarias $^{36}$, se comprendían como criminales tan poderosas que dominaban la

34 "No es suficiente con que el acusado responda: <<soy el autor de los delitos que se me imputan, y punto. Eso es todo. Juzguen, puesto que esa es su obligación y condénenme si les parece $>$. Al acusado se le pide mucho más, más allá del reconocimiento de sus acciones se le exige una confesión, un examen de conciencia, una explicación de sí mismo, una aclaración de lo que es él" (Foucault, La vida de los hombres infames, 1990, pág. 232).

35 "Estos grandes crímenes tienen también en común el hecho de que se desarrollan en la esfera doméstica. Son crímenes de familia, del hogar de la vecindad" (Foucault, 1990, p. 237).

36 "Se les llama <<maleficiarias >> a causa de la enormidad de sus crímenes, es decir, porque causan más mal que todo el resto de los malhechores, y añade: Entrechocan los elementos, por obra de los demonios, para traer pedriscos y tempestades, perturban la mente de los hombres, es decir, la inclinan a la locura, al odio, o al amor desordenado" (Jiménez, 2004, p. 52). 
naturaleza, perturbaban la mente de los hombres, los manipulaban para el odio, la locura y el amor insaciable. De manera preferente el diablo poseía a las mujeres, porque éstas son proclives a su poder ${ }^{37}$ esta afirmación estaba sentada en el imaginario de la penalidad de la edad media, sin mayor discusión. Por lo tanto, las mujeres encarnan la maldad, la malicia ${ }^{38}$ y son los peores seres que arrastran el odio, los vicios, la locura "el mal en la naturaleza pintado con buen color" (Jiménez, 2004, p. 1999) y por esto han de ser penadas de manera cruel para purificar el mundo, y proteger a los varones indefensos.

Otro de los sujetos peligrosos construidos por la penalidad, son los descritos en los casos de comienzos del siglo XIX que se erigieron en paradigmáticos con la ayuda de la psiquiatría en el orden penal, casos como el de Sélestat, Henriette Cornier, Catherine Ziegler entre otros, todos tratados como monstruos, sujetos anormales, peligrosos ${ }^{39}$ por sus acciones execrables, extrañas, crímenes graves, sin presentar síntomas o al menos los indicios tradicionales y conocidos de la locura, como el delirio, el trastorno del pensamiento, agitaciones o desórdenes de la conducta ${ }^{40}$. Lo que generó nuevas interpretaciones de los sujetos criminales funestos, y el castigo merecido para estos, sin que el recurso a la enfermedad

37 “En cuanto a la primera pregunta, por qué hay una gran cantidad de brujos en el frágil sexo femenino, en mayor proporción que entre los hombres; se trata en verdad de un hecho que resultaría ocioso contradecir, ya que lo confirma la experiencia, aparte del testimonio verbal de testigos dignos de confianza" (Jiménez, 2004, p. 98).

38 “De la malicia de las mujeres habla mucho el Eclesiástico: no hay peor veneno que el veneno de la serpiente, no hay peor odio que el odio de un enemigo (de la mujer). [...] Preferiría vivir con un león o con un dragón que con una mala mujer ...Y concluye: toda malicia es nada comparado con la malicia de una mujer qué otra cosa es la mujer sino la enemiga de la enemistad, la pena ineludible, el mal necesario, la tentación natural, la calamidad deseable, el peligro doméstico, el perjuicio delectable, el mal de la naturaleza pintado con buen color" (Jiménez, 2004, p. 99).

39 "Pudo estudiarse en ese sentido la evolución de la pericia médico legal en materia penal, desde el acto monstruoso problematizado a comienzos del siglo XIX (con los casos Cornier, Léger y Papavoine) hasta la aparición de la noción de individuo peligroso a la que es imposible atribuir un sentido médico o un status jurídico, no obstante lo cual es la noción fundamental de las pericias contemporáneas" (Foucault, 2001, p. 289).

40 “Un problema nuevo: el de los crímenes que no han estado precedidos, acompañados o seguidos de ninguno de los síntomas tradicionalmente reconocidos y visibles de la locura. En todos los casos se insiste en el hecho de que no había ningún síntoma previo, ningún trastorno del pensamiento o de la conducta, ningún delirio; que tampoco había existido agitaciones o desórdenes como sucedía en el caso del furor; es decir que el crimen surgía de lo que podría denominarse un grado cero de locura" (Foucault, 1990, p. 237) . 
mental, pudiese dar una comprensión o una justificación a individuos infractores de manera grave.

El religioso como sujeto peligroso emergente no responde a la consideración, de ser un individuo que presenta síntomas de locura, no es una explicación a sus acciones, no son pertinentes. Así que deja abierta la pregunta del porqué de sus acciones reprochables siendo un sujeto religioso, en especial como masculino. Quizá es hora de discutir esta problemática al interior de las Comunidades religiosas, para debilitar el sujeto religioso como peligroso y recuperar el lugar y la necesidad de su discurso alentador, de esperanza y de trascendencia que porta el religioso en tiempos de caída de la posmodernidad y el advenimiento de la era de la interconexión y la tecnologización de la vida individual y colectiva.

\section{El sujeto religioso masculino en las redes legales de la punibilidad}

Para comprender de qué manera en los albores del siglo XXI emerge de manera fuerte un sujeto punible que se centra en el religioso masculino que por defecto, en sus manifestaciones, en la intersubjetividad desplegada se avizora por los otros, como un sujeto peligroso con una actividad sexual reprensible. Este sujeto masculino nocivo en el que se ha convertido al religioso, no surge de forma desprevenida o espontánea, sino que es la consecuencia, de que algunos religiosos han incurrido en acciones reprensibles, y de manera específica en contra de un sujeto de especial y prevalente amparo, lo que hace que estos y los ilícitos perpetrados sean juzgados y condenados de manera fuerte, sin justificaciones, ni atenuantes y menos aún, sin algún tipo de conmiseración o explicación más allá de la conducta misma. Por otro lado, es de especial atención que para la comunidad interconectada, virtualizada, se ha transformado tanto sujeto como discurso, en ilícito, en infractor, en foco de castigo, persecución, censura, reproche, y sin duda violencia no sólo de parte del legislador, fiscales y jueces, sino por parte de cualquier persona que se legitima para enrostrar su delito, y que lo hacen desde las vitrinas globalizadas desde los blogs, las páginas web, la televisión o la radio ${ }^{41}$ como antiguamente se hacía con las brujas, los locos y en últimas los anormales. Como

41 "Como el caso de la entrevista realizada a un religioso franciscano, en la emisora colombiana la $\mathrm{W}$ radio, quien es juzgado y condenado por un periodista, quien sin ninguna consideración le imputa el delito, además de tratarlo de manera violenta, y severa, sin pruebas, sin defensa, sin presunción, ni garantías mínimas. Lejos de las salvaguardas procesales propias del orden penal" (Sánchez, 2015). 
sujetos emergentes y por la calidad y condición de la que gozan, estos ilícitos y el juicio adelantado a los sujetos religiosos masculinos, se han configurado en verdaderos eventos públicos, gracias a la globalización, la exhibición y la sensibilización global cristiana compartida que ha sido ofendida. Es fundamental que el sujeto religioso caído dentro de los juicios fuertes de la punibilidad, no surge de manera espontánea, ni desprevenida, pues obedece no solo a la secularización, a la crisis del sujeto religioso, sino a los juicios, condenas y pago de multas que desde el año de 1985 se han llevado a cabo a religiosos por el delito de pederastia en países como EEUU ${ }^{42}$ (primer país en adelantar estos juicios), México, Argentina, Alemania, Bélgica, entre otros. En el caso de Colombia, también han sido investigados y condenados religiosos por delitos sexuales con menores de edad, y por primera vez es condenada la Iglesia Católica, -como institución- al pago de una fuerte indemnización por este delito.

La Corte Suprema de Justicia, en sentencia SC 13630 de 2015, hace afirmaciones quizá controvertidas, pero interesantes; condena civilmente por responsabilidad directa y solidaria a la Diócesis de Líbano- Honda (Tolima) por el delito cometido por uno de sus sacerdotes (quien es condenado penalmente a 220 meses de prisión, por el delito sexual). Señala que existe una evidente subordinación de los sacerdotes respecto de su Diócesis, porque estos cumplen un cometido público eclesiástico a nombre de esta ${ }^{43}$; lo que la convierte en responsable por los actos ilícitos de sus ministros, en razón al deber de control, vigilancia y cuidado, que le corresponde $\mathrm{e}^{44}$. Señala que la Iglesia católica posee un peculiar estatus de

42 “El abuso sexual por parte de sacerdotes se convierte en una cuestión nacional por primera vez en Estados Unidos cuando el párroco de Luisiana, Gilbert Gauthe es encontrado culpable de once casos de abuso a menores" (BBC Mundo, 2010).

43 Cfr. Corte Suprema de Justicia, Sala de Casación Civil, Sentencia SC 13630 de 2015 M.P. Ariel Salazar Ramírez “No hay duda que el oficio sacerdotal es un encargo público eclesiástico y quien lo desempeña lo hace a nombre de la Iglesia a la que pertenece, de manera que la responsabilidad civil derivada del ejercicio abusivo de ese ministerio es institucional de la organización religiosa, por lo que la Iglesia tiene la obligación legal de reparar los daños que un clérigo causa a sus feligreses en razón o con ocasión del desempeño de su misión pastoral, tanto espiritual como terrenal".

44 Cfr. Corte Suprema de Justicia, Sala de Casación Civil, Sentencia SC 13630 de 2015 M.P. Ariel Salazar Ramírez "Los entes morales responden directamente por los actos culposos y dolosos de sus agentes que causan un daño resarcible a terceros en razón y con ocasión de sus funciones o prevalidos de la posición que ocupan en la organización [...] De ahí que resulte absolutamente innecesario tratar de demostrar que la persona jurídica demandada tenía o no el deber de vigilancia y control sobre el sacerdote, pues tratándose, como se trata, de un tipo de responsabilidad directa, no se requiere en absoluto la prueba de tal situación fáctica" 
ser persona jurídica de derecho público eclesiástico, y recuerda que ella cumple el propósito de conservar la moral pública, y la protección del derecho fundamental a la libertad religiosa y de cultos, por lo que debe resarcir el daño de forma integral más allá de lo pecuniario, como pedir perdón público, brindar ayuda espiritual a las víctimas, entre otras reparaciones administrativas y simbólicas, como quiera que la ofensa es a un bien jurídico superior protegido, que repercute no solo a los creyentes, sino a la sociedad entera ${ }^{45}$. Establece que la ley canónica es solo el estatuto orgánico de la entidad y en ningún caso se trata de una norma coercitiva, ni de valor de norma jurídica externa o interna ${ }^{46}$ que imponga restricciones, licencias o estatus especial a los ciudadanos.

\section{Los retos para recuperar al sujeto religioso masculino de la punibilidad}

Ante la puesta y apuesta fuerte de la penalidad posmoderna, que ha construido como peligroso, al religioso masculino, quien es considerado reprensible. Más allá, parece que cualquier forma de acercamiento con los niños y menores, es sujeto de interpretación, en la cual está comprometido de manera cierta su deseo insano de lesionarlo o de aprovecharse para su gozo personal. Parece que no hay mediación, ni comprensión distinto a que es un sujeto -todos como sujeto-quien de manera indiscriminada dirige sus acciones a satisfacer sus deseos irrefrenables. Esta construcción a manera de imaginario social, -sin desconocer los actos reprochables juzgados y condenados de algunos ha de reconducir a un espacio comunitario de comunicación, en donde se privilegie la autocrítica, la autorreflexión, acerca del compromiso y el rol sensible que cumplen en las complejas vidas en conjunto del siglo XXI; porque más allá de la misión como cristianos comprometidos y consagrados, tienen el propósito superior de garantizar la fe, la creencia de los ciudadanos, en términos de los fines sociales del Estado social de derecho.

45 Cfr. Corte Suprema de Justicia, Sala de Casación Civil, Sentencia SC 13630 de 2015 M.P. Ariel Salazar Ramírez "En tanto el daño causado por la Iglesia a sus feligreses por los delitos sexuales cometidos por sus clérigos repercute gravemente no sólo en los fieles sino en la sociedad entera-dada la doble dimensión terrenal y espiritual de esta organización".

46 Cfr. Corte Suprema de Justicia, Sala de Casación Civil, Sentencia SC 13630 de 2015 M.P. Ariel Salazar Ramírez "La ley canónica no tiene fuerza coercitiva no se le da valor de norma jurídica (externa ni interna), sino que se la considera simplemente como el estatuto orgánico de una entidad religiosa, tal como lo tienen las demás iglesias y confesiones". 
Quizá sea urgente pensar la vuelta o el retorno, a unas formas de ser, decir y actuar del religioso de la posmodernidad, en términos más de un sujeto consagrado, menos mundano, menos inserto en las cotidianidades, y urgencias del practicante común. Lo que conlleva las exigencias propias, de un hombre ante todo creyente, con una fe inquebrantable, un estudioso del hoy para poder interpretarlo, un hombre que se autogobierna, y pese a todo asumir una discreta manera de vivir y asumir los vicios. Solo en la medida que se reconstruya como sujeto consagrado, dejará de ser objeto de la punibilidad actual, en donde es centro de reproche, desconfianza en su persona y en el discurso que lo gobierna; no hay duda que son fuertes las realidades del presente como el consumo, la exhibición, las tecnologías, que lo han configurado en objeto indiscriminado de improperios, criticas duras, y objeto de una posible oportunidad de ganancia económica.

Vale retomar la reflexión de Lacan acerca de la práctica del psicoanalista como un santo, un santo, que responde a la relectura de la propuesta de Gracián ${ }^{47}$, en donde señala que una vida de quien opta por la cura mediante la escucha, no debe perturbar, no debe trastornar, por lo que ha de atender a tres compromisos básicos, el primero no gozar ${ }^{48}$, es decir no dejarse arrastrar por el exceso, ha de ser moderado, atemperado, en la conducción de su existencia; él busca la ponderación, nunca los límites, lo extremo. El otro aspecto de la razón práctica de quien decide ser santo, es el saber callar, guardar silencio, reservar a su fuero interno lo oído, lo que el Otro, y los otros desean que permanezca oculto. O cuyo deseo sea que el analista se convierta en el destinatario de lo secreto, ardua tarea solo escuchar, oír y enmudecer. Y por último, la exigencia de este santo recae en que en el desenvolviendo, en sus actos exteriores, visibles y, en últimas; que toda su vida pública, dé cuenta de una vida de pundonor. Que para y ante la mirada de los otros, sus acciones sean contenidas, han de parecer propias de un santo. Este santo también tiene otro principio junto al no alborotar, debe reírse. Estas exigencias para la práctica de quien opta por la escucha, quizá sean oportunas y no lejanas, ni exóticas para un hombre que decide consagrar su vida al servicio de los otros, a la cura del alma.

47 “Ocupémonos pues del psicoanalista. [...]No podríamos situarlo mejor objetivamente sino con lo que en el pasado se llamó ser un santoNadie se da cuenta de ello cuando sigue la vía de Baltasar Gracián: la de no alborotar" (Lacan, 2012, p. 545).

48 "Para el santo la cosa no es divertida. [...] Solo el santo se queda seco; para él ni pizca. Hasta es eso lo que más deja pasmado en este asunto. Deja pasmados a quienes se aproximan a eso y no se equivocan: el santo es el desecho del goce" (Lacan, 2012, p. 546). 


\section{Conclusiones}

La posmodernidad o lo que queda de ella, trae consigo la crisis del sujeto y del discurso que lo gobierno, la desconfianza generalizada hace que la seducción por los iconos, tengan la suficiente fuerza como para reemplazar los imponderables de la vida el hombre.

La fragmentación del sujeto y del discurso, hace que la consideración o la reconstrucción de este, sean dentro de una arquitectura fractal, de redes, en donde no se trata de unidad, sino de multiplicidad, no un sujeto, sino sujetos que lo configuran. De nichos simbólicos de creación, de convergencia.

El sujeto religioso masculino está dentro de la lógica de las rupturas, de los metacentros de lo posmoderno, de ahí que es coherente su caída, y la sospecha que representa para el hombre de hoy, bimilenario caminando en mundos y redes cuánticas.

El hombre consagrado en su caída, ha sido recogido para ser juzgado por el orden legal, que retoma los imaginarios, de la penalidad sobre qué se ha de castigar, a quién, y cuánta pena se ha imponer al infractor.

Quedan retos al hombre religioso masculino para recomponer la vida consagrada como vida ejemplar, para los otros, para el Otro, y cumplir los bienes jurídicos superiores que le son confiados dentro de los fines del Estado social de derecho.

\section{Referencias}

Baudrillard, J. (2000). Las estrategias fatales. Barcelona: Anagrama.

Baudrillard, J. (2009). El crimen perfecto. Barcelona: Anagrama.

Bauman, Z. (2010). Tiempos líquidos . Barcelona: Tusquets.

BBC Mundo. (22 de Abril de 2010). http://www.bbc.com/mundo/internacional/ 2010/03/100326_timeline_abuso_sexual_iglesia_pl.shtml. En: http://www.bbc. com/mundo/internacional/2010/03/100326_timeline_abuso_sexual_iglesia_ pl.shtml: http://www.bbc.com/mundo/internacional/2010/03/100326_timeline_ abuso_sexual_iglesia_pl.shtml. Recuperado: 12/11/2015.

Cárcova, C. (2012). Las Teorías Post Positivistas. Buenos Aires: AbeledoPerrot.

Corte Suprema de Justicia, Sala de Casación Civil, Sentencia SC 13630 de 2015 M.P. Ariel Salazar Ramírez

Evans, D. (1997). Diccionario introductorio de psicoanalisis lacaniano. México D. F.: Paidós. 
Foucault, M. (1990). La vida de los hombres infames. Madrid: Enddymion.

Foucault, M. (2001). Los anormales. México: Fondo de Cultura Económica .

Garland, D. (2010). Castigo y sociedad moderna. México: Siglo Ventiuno editores .

Grimm, D. (2007). Derecho constitucional para la sociedad multicultural. Madrid: Trotta.

Jiménez, M. (2004). El martillo de las brujas. Valladolid: Maxtor.

Lévinas, E. (2008). Ética e infinito. Madrid: La balsa de la medusa.

Lipovetsky, G. (2006). La era del vacío. Barcelona: Anagrama.

Lipovetsky, G. (2008). La sociedad de la decepción. Barcelona: Angrama.

Ruiz de Samaniego, A. (2004). La inflexión posmoderna: los márgenes de la modernidad. Madrid: Akal.

Ruiz, A. (2006). Aspectos ideológicos del discurso jurídico (desde una teoria crítica del derecho). En M. Enrique, Materiales para una teoria crtica del Derecho (págs. 99109). Buenos Aires: Abeledo-Perrot.

Sánchez, J. (30 de Septiembre de 2015). http://www.wradio.com.co/. En: http:// www.wradio.com.co/escucha/archivo_de_audio/jamas-he-violado-a-nadiepadre-federico-fernandez/20150930/oir/2951974.aspx: http://www.wradio.com. co/escucha/archivo_de_audio/jamas-he-violado-a-nadie-padre-federicofernandez/20150930/oir/2951974.aspx. Recuperado: 15/11/2015.

Santos, B. (1998). La globalización del derecho. Santafé de Bogotá: UNIBIBLOS.

Vattimo, G. (1998). La sociedad transparente. Barcelona: Paidós.

Wittgeintein, L. (1999). Investigaciones Filosóficas. Barcelona: Altaya.

Yañez, H. (2003). La interioridad, genésis de la socialidad. En P. R. al, La ética del compromiso (pp. 247-260). Buenos Aires: Altamira. 